\title{
Cross-cultural common denominators of the mentoring in biomedicine
}

\author{
Matko Marušić \\ Department of Research in Biomedicine and Health \\ School of Medicine, University of Split, Split, Croatia \\ ${ }^{*}$ Corresponding author: \\ matko.marusic@mefst.hr \\ Tel./ Fax.: +385 21557820
}

Received/Accepted: 24 May 2015

Key words: Education medical graduate -

Mentors - Evidence-Based Medicine

In his „ecological model of mentoring“ $\mathrm{Dr}$ Sambunjak (1) covered all aspects of wider environmental influences on mentoring. I would like just to emphasize some of his points, which I believe are present in all environments in which a young scientist strives to do the research required for the $\mathrm{PhD}$ thesis. I have experienced them with a number of doctoral fellows, including the author himself (2).

1. PhD candidate should know that a decent thesis cannot be done without "blood, sweat and tears". Hard work. Many years. Lots of failures and disappointments. However, science is not like football, where one can lose a well-played match because the goalkeeper had two last-minute mistakes; in science failures do not count, only successes.

2. The doctorate is not homework, but a pathway to becoming a scholar, someone who has gained master skills in a certain field. $\mathrm{PhD}$ training is aimed at young people who have chosen to do research throughout their careers, regardless of the field of medicine in which they will work.

3. "Enlightened routine" is a slogan which emphasizes that the PhD-related research should be done at the very workplace at which the student is employed. Working "overtime" in another institution for the $\mathrm{PhD}$ thesis is a wrong decision, for organizational reasons and reason given in the previous paragraph. Enlightened routine means that a part of routine, everyday work should be "wrapped" into a hypothesis and investigated thoroughly, as it should be done in good research project (3).

4. Plan of the research must be meticulously prepared, starting with the hypothesis, type of study, the sample, outcome measures, and other, all to the list of the potential authors of the research report and their envisioned contributions (4).

5. Rush slowly - acting zealously implies more intensive work, which is fine, but good research needs perfect planning, preliminary experiments, technical perfection, preparing carefully day before experiment or procedure scheduled tomorrow, discussions, and other sophisticated skills; so, one has to - rush slowly, carefully; see also No. 2 above.

6. The mentor should be the best mentor for the thesis. There are many potential 
mentors around, but few are suitable because inadequate mentors prevail. Fortunately, today all data are on the internet; if the mentor has not published well, and especially if unproductive in recent times, he should be avoided: if the mentor does not publish, there is high chance that the $\mathrm{PhD}$ student will not, either.

7. Medical schools should improve their $\mathrm{PhD}$ programs and overall research-promoting efforts by introducing into their obligatory graduate curricula the evidence-based medicine (EBM) concept and work (5). EBM requires good understanding of scientific principles and technology of reasoning, criteria of excellence and critical thinking, and makes literature reading more easy, selective and critical. Using the EBM approach, School of Medicine in Split has increased its graduation rate of one reformed doctoral program to around 60\% (Sapunar D, personal communication, 2015).

Conflict of interest: The author declares that he has acted as a mentor and close collaborator of Dr Dario Sambunjak.

\section{References}

1. Sambunjak D. Understanding wider environmental influences on mentoring: Towards an ecological model of mentoring in academic medicine. Acta Med Acad. 2015;44(1):47-57. DOI: 10.5644/ ama2006-124.126.

2. Sambunjak D, Marušić M. Between forwarding and mentoring: a qualitative study of recommending medical doctors for postdoctoral research abroad. BMC Medical Education. 2011, 11:3. doi: 10.1186/1472-6920-11-31.

3. Marušić A, Marušić M. Can small journals provide leadership? Lancet. 2012;379:1361-3. doi:10.1016/ S0140-6736(11)61508-0.

4. Marušić A, Malički M, Sambunjak D, Jerončić, Marušić M. Teaching science throughout the sixyear medical curriculum: Two-year experience from the University of Split School of Medicine, Split, Croatia. Acta Med Acad. 2014;43(1):50-62. DOI: 10.5644/ama2006-124.100.

5. Grković I, Sapunar D, Marušić M. Ways to address challenges of a modern medical curriculum: living academic medicine at the University of Split School of Medicine. Acta Med Acad. 2012;41(1)717. DOI: 10.5644/ama2006-124.31. 